\title{
TRANSGRESSÃO, CONTROLE SOCIAL E RELIGIĀO: UM ESTUDO ANTROPOLÓGICO SOBRE PRÁTICAS RELIGIOSAS NA PENITENCIÁRIA FEMININA DO ESTADO DO RIO GRANDE DO SUL
}

\author{
Gilse Elisa Rodrigues
}

Pontificia Universidade Católica do Rio Grande do Sul

Resumo: Este artigo é resultado de um estudo feito em uma penitenciária feminina e propõe uma reflexão sobre as possibilidades de reorganização das biografias de mulheres reclusas no sistema carcerário do Estado do Rio Grande do Sul a partir das práticas religiosas. Atenta-se para a utilização que elas fazem de elementos da linguagem religiosa que os evangelizadores colocam à sua disposição como forma de proteção de suas identidades. A análise centra-se especificamente no jogo interacional entre presas, evangelizadores e representantes da instituição prisional.

Palavras-chave: conversão, crime, linguagem religiosa, mulheres aprisionadas.

Keywords: conversion, crime, imprisioned women, religious language.

Atualmente podemos assistir a uma intensa atuação de grupos desvinculados do Estado que buscam a melhoria das políticas referentes ao sujeito incluso no sistema prisional. As instituições religiosas compõem uma parcela significativa nesse processo, demarcando um território importante de atuação na esfera religiosa. Diferentes denominações religiosas, através de seus evangelizadores, seguem em busca das "ovelhas desgarradas" que o sistema de punição vigente isolou dentro das prisões e invariavelmente, com suas políticas de reabilitação, não consegue reintegrar ao "rebanho".

Tendo como ponto de partida essa constatação, iniciei no ano de 2000, dentro do programa de Pós-Graduação em Antropologia Social da Universi- 
dade Federal do Rio Grande do Sul, um estudo, de caráter etnográfico, contemplando as relações estabelecidas entre mulheres aprisionadas e agentes de instituições religiosas que atuavam dentro da Penitenciária Feminina do Estado do Rio Grande do Sul. Minha intenção naquele momento era compreender as possibilidades que tais relações estariam trazendo para as mulheres em privação de liberdade, no que se refere à reorganização de suas trajetórias e biografias através de elementos retirados da linguagem religiosa.

Buscava, assim, uma "descrição densa” (Geertz, 1989), não da instituição em sua totalidade, mas das interações entre os indivíduos envolvidos em um drama social que lá se desenrolava. A prioridade eram as percepções e narrativas das apenadas na sua interação com evangelizadores, bem como as possibilidades de conversão religiosa ou adesão, abordando de forma secundária a dimensão institucional.

O presente artigo refere-se ao estudo da atuação de grupos religiosos dentro de uma penitenciária feminina e resulta de um apanhado de questionamentos, observações e reflexões que integram em grande parte o texto final de minha dissertação de mestrado.

Tendo em vista as limitaçóes inerentes ao cotidiano do sujeito aprisionado, busquei identificar as possíveis estratégias criadas pelas reclusas com o intuito de minimizar as conseqüências do processo de prisionização a que estão sujeitas quando da inserção no sistema penal. Que possibilidades o sujeito tem de "cuidar" do self, tomando aqui a estratégia religiosa como uma "terapêutica" possível dentro desse contexto de "deterioração do eu". ${ }^{1}$

Pensando no processo de prisionização nos termos de Erving Goffman (1978), proponho um entendimento da conversão ou adesão religiosa como um mecanismo para reorganizar a vida dentro da prisão, promovendo novas formas de proteção da identidade do sujeito.

\footnotetext{
1 As noções de mortificação e deterioração do eu apóiam-se em Goffman (1978), sendo vistas como um processo pelo qual a instituição ajusta o detento promovendo a perda total da autonomia até mesmo na realização das atividades mais banais da vida cotidiana. E a prisionização, segundo o mesmo autor, refere-se à superação total da identidade anterior ao aprisionamento.
} 
Torna-se necessário, dentro da perspectiva antropológica desse estudo, entender a conversão intramuros não como uma "falsa conversão", mas como um processo de transformação do sujeito com dimensões e significados próprios. A religião pode ser também uma linguagem da qual essas mulheres lançam mão para solucionar conflitos decorrentes do drama social que o aprisionamento representa.

Embora me afaste da noção clássica de conversão, resolvi não abrir mão desse conceito tão caro aos estudos sobre religião, mas propor uma relativização do mesmo. Acredito ser necessário na análise da conversão religiosa, no caso específico desse estudo, levar em consideração as novas modalidades de conduta religiosa marcadas por vulnerabilidades e opções menos totalizantes. Percebo, portanto, a conversão como "a aceitação de um novo locus de identificação, um novo, porém, não exclusivo ponto de referência” (Hefner, 1993, p. 17, tradução minha) a partir do qual o indivíduo reorganiza e subsidia sua identidade social. Além disso, a religião encarada como um sistema cultural, uma "rede de significados", possibilita interpretações e modificações resultantes de um processo comunicacional característico do jogo interacional entre atores sociais negociando a realidade.

Os discursos tanto dos representantes da instituição prisional quanto das evangelizadoras que deram depoimento vão no sentido da minimização dos conflitos, quando falam sobre as atividades religiosas na famosa "panela de pressão" que são as prisões o Brasil. Mas as alianças e discursos comuns não são absolutos. Muitas vezes as evangelizadoras podem aparecer como aliadas das apenadas, mediadoras entre estas e a instituição, às vezes mesmo defendendo seus interesses frente à equipe técnica.

É aí que reside a especificidade e o interesse de pesquisa, na medida em que esses agentes religiosos podem estar minando a organização institucional e possibilitando algum nível de autonomia às presas. Não pretendo com isso afirmar, de forma ingênua ou precipitada, que as evangelizadoras são um elemento desestabilizador da ordem interna da instituição, mas que estas podem sim estar evidenciando uma estratégia do poder público (configurado na instituição prisional) de repassar às instituições religiosas, bem como outras organizações não estatais que atuam dentro da penitenciária (como 
ONGs e outros grupos de apoio capitaneados pela sociedade civil), a solução dos conflitos decorrentes de um processo de mortificação, deterioração das identidades que os sujeitos enfrentam dentro de uma instituição total, ${ }^{2}$ e que em função da grande discussão sobre humanização das prisões e direitos dos presos passam a ser questionados e criticados por boa parte da sociedade civil.

O início da pesquisa concentrou-se nas observações dos momentos de culto. Mas à medida que fui aprofundando a pesquisa de campo e intensificando minha convivência com os sujeitos pesquisados, pude ampliar minha participação na rotina da instituição. Certamente, aqueles momentos, à primeira vista especificamente de atividade religiosa, traziam consigo muito mais do que religiosidade, o que pode ser explicado pelo fato de que as fronteiras da esfera religiosa na contemporaneidade, assim como as demais esferas da vida social, tornam-se mais porosas, abrindo espaço para negociações e trocas dos mais diferentes matizes, com influências mútuas entre as esferas. ${ }^{3}$

Esse fato permite ao sujeito "religioso" circular em busca de elementos culturais muito diferentes e por vezes contraditórios, libertando-se das "amarras de uma identidade estruturada” (Carvalho, 1991). Para alcançar meu empreendimento científico, apresento nesse estudo três aspectos que me parecem fundamentais: primeiro, descrever que espaço é este que está servindo de cenário para as tais negociações de caráter religioso e extra-religioso. Em outras palavras, um mapeamento com caráter etnográfico da instituição prisional em questão. Segundo, como se configura o mercado religioso dentro da penitenciária. Que denominações estavam atuando lá dentro no período da pesquisa. Terceiro, quais os diálogos possíveis entre estes três atores sociais

2 Utilizo a noção de instituição total apresentada por Goffman (1978, p. 11) como um tipo ideal, sofrendo variações significativas na abordagem empírica das instituições prisionais, mantendo, porém, alguns aspectos recorrentes: "um local de residência e trabalho onde um grande número de indivíduos com situação semelhante, separados da sociedade mais ampla por um considerável de tempo, leva uma ida fechada e formalmente administrada”.

${ }^{3}$ Como salienta Steil (1998), em um contexto de modernidade o campo religioso, a exemplo de outros setores, apresenta uma "mixagem de gêneros" com o cruzamento entre religião, ciência, filosofia, psicologia, diluindo-se as fronteiras do religioso. 
que seriam para mim os protagonistas deste drama social que se desenrola no cotidiano intramuros: agentes religiosos, equipe dirigente e detentas. Que relações se estabelecem entre eles?

\section{A PENITENCIÁRIA FEMININA MADRE PELLETIER}

Importa ressaltar, inicialmente, o processo histórico de fundação da instituição penal em questão: uma penitenciária que, no princípio (nos anos 1940), era uma casa correcional, mantida e administrada por uma congregação católica ${ }^{4}$ (a congregação do Bom Pastor, fundada no século XIX pela madre francesa Maria Eufrásia Pelletier), que com o passar dos anos e em função do processo de separação entre Igreja e Estado, e com a constituição de um Estado laico, afastou-se formalmente do serviço de reeducação de presidiárias, deixando o mesmo a cargo estatal. Tal congregação passa, a partir dos anos 1980, com o processo de redemocratização do país no final da ditadura militar e em função do estabelecimento de um mercado religioso, a entrar apenas como mais uma possibilidade para o sujeito preso, que alcançava, através da LEP (Lei de Execução Penal), ${ }^{5}$ o direito à liberdade religiosa, bem como o direito de exercer sua religiosidade dentro do espaço prisional.

No que se refere ao aspecto organizacional da penitenciária, em função do seu caráter de instituição totalizante, o controle se mostra evidentemente em sua dimensão mais intensa. Controle rígido de horários, controle através de sistema interno de vídeo, controle do fluxo de pessoas. ${ }^{6}$

${ }^{4}$ Essa é uma característica principalmente das prisóes femininas, que começam a ser construídas no Brasil no início do século XX.

5 A Lei de Execução Penal 7.210, sancionada em 11 de julho de 1984, define que a assistência ao preso inclui assistência religiosa com liberdade de culto, devendo ter lugar apropriado dentro da instituição para a realização de tais práticas.

${ }^{6}$ É interessante ressaltar que esse "rígido controle" pode ser amenizado ou até mesmo "esquecido" em meio à vida diária. Percebi isso quando, depois de algum tempo de pesquisa, conseguia entrar sem grandes obstáculos, e circulava pela instituição sem o mesmo monitoramento inicial. 
Esse controle, evidentemente, não se restringe às instituições totais, como bem salientou Foucault (1999). Hoje, assistimos de forma generalizada a um intenso monitoramento em escolas, empresas, residências, espaços públicos, não só como forma de controle da violência, mas certamente também como estratégia de disciplinamento.

Aqui se torna central a questão do poder dentro da instituição e as possibilidades dos atores sociais de negociarem a vida cotidiana, através de papéis sociais diferenciados alcançando direitos, privilégios, regalias e punições. Existem as regras oficiais da instituição e existem as regras que surgem das relações da vida cotidiana.

Os horários dos encontros religiosos são definidos obviamente pela administração da penitenciária, de acordo com as possibilidades de monitoramento por parte da equipe dirigente. ${ }^{7}$ Esta detém o controle sobre as possibilidades de participação das detentas que depende muitas vezes do "bom comportamento", mas isto também é passível de negociação, como me confirmou um agente penitenciário:

[...] quando estão muito rebeldes, elas sabem que não podem descer para o culto. Eu não deixo, mas tem gente que acha que a participação no culto pode melhorar o comportamento. Vai depender de quem tá no controle no dia. (Caderno de campo).

\section{O MERCADO RELIGIOSO DENTRO DA PENITENCIÁRIA}

O mercado de bens e serviços religiosos dentro da penitenciária, a exemplo da sociedade mais ampla, é bastante diversificado. Atuavam, até maio de 2002, quando encerrei minha pesquisa de campo, grupos pentecostais, católicos, espíritas, e havia uma atuação não-oficial de afro-brasileiras. Além dis-

7 Das 130 mulheres (esse número podia variar conforme as constantes entradas e saídas em função sobretudo das prisões preventivas ou temporárias) que integravam a população carcerária da penitenciária no período da pesquisa, em torno de $50 \%$ freqüentavam os cultos, às vezes em mais de uma denominação religiosa. 
so, pude detectar uma devoção popular não institucionalizada que constituise naquilo que denominei "lenda da Madre Pelletier", ${ }^{8}$ além de práticas de ocultismo, tarô, com uma significativa profusão de histórias marcadas pelo misticismo.

Essas práticas não oficializadas dentro da prisão sofrem um certo escamoteamento, sendo consideradas tanto por funcionários da casa quanto pelas detentas como práticas perigosas, cujas conseqüências seriam de difícil solução dentro do espaço prisional. Isso pode ser entendido, em parte, pela crença bastante difundida de que a prisão seria um lugar propício para a atuação de "espíritos sofredores", na linguagem espírita, para a "ação do demônio", na linguagem pentecostal, ou, no mínimo, um lugar com uma "energia pesada” ou negativa, na linguagem do senso comum. A dimensão mágico-religiosa que perpassa o imaginário brasileiro estaria fornecendo elementos importantes para essas representações.

\section{AS RELAÇÕES ENTRE ESTADO, INSTITUIÇÕES RELIGIOSAS E MULHERES TRANSGRESSORAS E A VIABILIDADE DE UMA CONVERSÃO OU ADESÃO RELIGIOSA NO ESPAÇO PRISIONAL}

Os limites do Estado, no que tange à reabilitação do apenado, são muitas vezes confrontados com a atuação dos grupos religiosos que, no fim, atuam muito mais na busca de um apoio emocional do que propriamente de adesão religiosa. Como afirmou uma agente da Pastoral Carcerária: "não há no nosso trabalho um propósito de denominação. O que nós queremos

\footnotetext{
${ }^{8}$ Esse fato está descrito de forma mais detalhada em minha dissertação de mestrado (Rodrigues, 2002) e refere-se à crença de algumas apenadas, principalmente aquelas que participam de cultos católicos e espíritas, na presença do espírito de Madre Pelletier nas dependências da prisão. Sendo que aquelas que vêem a Madre estariam recebendo o sinal de que seriam absolvidas. Além disso, existem imagens da Madre pela instituição o que acaba por reforçar a devoção de algumas presas.
} 
despertar nelas é paciência e perseverança, independente da religião que elas querem seguir."

A apropriação da linguagem de diferentes sistemas religiosos pode proporcionar uma interlocução entre os mesmos, e essa interlocução pode ser evidenciada pelas negociações com os diferentes agentes religiosos atuantes dentro da instituição prisional.

Ao observar as diferentes manifestaçôes religiosas dentro da penitenciária, podemos visualizar possibilidades limitadas de conversão (no sentido tradicional de uma conversão paulina) e, ao mesmo tempo, uma forte referência ao que se denomina hoje de "passagens" (Birman, 1996), promovendo aqueles espaços de interlocução entre sistemas diferenciados de crenças. Retomo, assim, a noção de conversão com uma especificidade em dois sentidos: por um lado, em função do espaço prisional, que facilita a interlocução, visto que as diferentes denominaçôes convergem para um mesmo local; por outro lado, a condição reclusa, transgressora e de exclusão dos sujeitos definindo a especificidade do indivíduo religioso nesse contexto, que pode estar se constituindo ou reformulando antigas crenças.

Além disso, o processo de conversão pode ser analisado em duas dimensões: em uma dimensão individual (Mafra, 2000) a conversão aparece como recurso lingüístico da mulher aprisionada para reorganizar a própria biografia após o momento dramático do aprisionamento. Por outro lado, em uma dimensão coletiva - no que se refere ao grupo ao qual o sujeito adere - a conversão está configurando redefinições de fronteiras e reelaborações simbólicas tanto para os novos convertidos quanto para os convertedores, em função do jogo interacional que os atores sociais estão promovendo.

Nesse jogo as detentas selecionam elementos dos sistemas religiosos e ressignificam suas práticas sociais se situando dentro de contextos diferenciados (as diferentes esferas da vida social que se reproduzem dentro da prisão, visto que a instituição total reproduz em grande parte a forma de organização da sociedade mais ampla), na sua relação com os evangelizadores, com os agentes penitenciários, além de criarem novas possibilidades de relacionamento com as experiências anteriores ao aprisionamento, como os rompimentos familiares, que são bastante recorrentes nos depoimentos colhidos ao longo da pesquisa de campo. 
Uma das especificidades da interação apenadas/agentes religiosos é que as instituições religiosas não estão diretamente atuando dentro da organização. As evangelizadoras parecem gozar de uma certa autonomia ali dentro no que se refere às negociações, isso porque nesse espaço elas precisam muitas vezes adaptar princípios e valores que podem estar distantes da realidade das mulheres encarceradas.

Um questionamento que surge dessa reflexão refere-se às possíveis influências dessa interação intramuros sobre as reformulações que os cultos desses novos movimentos religiosos sofrem constantemente, principalmente no que tange à atuação mais intensiva de mulheres enquanto agentes religiosos. São elas, de forma predominante, que entram na prisão feminina e aproximam as possíveis fiéis da doutrina da instituição, fazendo muitas vezes uma tradução para uma realidade diferenciada.

Acredito que, ao se movimentarem nesses espaços de interlocução que se produzem a partir da esfera religiosa, tanto evangelizadoras quanto detentas exercitam novas posiçôes sociais, uma certa autonomia, uma "liberdade de escolha”, que não se restringe à liberdade religiosa. Dentro de uma instituição total que, como já foi falado anteriormente, promove uma profunda desestruturação do indivíduo, o discurso religioso oferece às presas uma possibilidade de se pensarem como sujeitos atuantes dentro da sociedade, uma inserção mais positiva, além do recurso para refletirem sobre sua responsabilidade sobre o crime cometido, ainda que essa reflexão possa estar sendo definida exclusivamente pela perspectiva do sistema de valores da instituição religiosa, principalmente no caso das pentecostais, que cada vez mais demonstram uma capacidade de interferir significativamente nas culturas, reelaborando e reinterpretando elementos e categorias fundamentais das mesmas.

No que se refere à instituição prisional e aos limites impostos ao sujeito nela confinado, percebe-se que poucos são os serviços e programas promovidos pela administração que conseguem efetivamente envolver a mulher presa. A desconfiança, o medo de ser mal interpretada, os segredos e pactos que caracterizam o cotidiano desse tipo de instituição são aspectos importantes para que as mulheres internas do sistema penitenciário não participem efeti- 
vamente desses programas. Há uma distância e um conflito que parece insolúvel entre sujeito aprisionado e equipe de técnicos e profissionais encarregados do processo de reeducação. Embora exista uma necessidade de ambos os lados de manter as distâncias e evitar contaminaçôes através de hostilidades e estereótipos, em diferentes momentos da vida cotidiana ocorrem paralelamente as aproximações, alianças, clientelismo, proteções que proporcionam a flexibilização do sistema para que ele consiga continuar existindo.

Os agentes religiosos atuam, de um modo geral, neste vazio deixado pelo poder público, realizando serviços que oficialmente seriam dos profissionais e técnicos da instituição. Extrapolam a "função" inicial de apoio espiritual, isso na visão da própria instituição prisional, e assumem um papel preponderante de conselheiros, mediadores entre as internas e o mundo externo, com a equipe técnica e dirigente, muitas vezes substituindo até mesmo a família no que tange ao apoio emocional e afetivo.

A viabilidade de um sistema explicativo proporcionando uma interpretação para o sofrimento muitas vezes é o que dá sustentação ao convertido e permite a manutenção do vínculo com o agente religioso e com o sistema de crenças que ele propõe. Poder reordenar a própria biografia, explicar o aprisionamento e reinterpretá-lo como uma forma divina de protegê-las ou afastálas de um mal maior, configura uma tendência que os relatos colhidos demonstram:

Foi Deus que me colocou aqui dentro, pra me impedir de fazer uma coisa pior.

Deus sabe o que faz. Se eu não tivesse que passar por isso eu não estava passando.

Eu acho que isso aqui [a prisão] faz parte do meu crescimento espiritual.

Finalizando, eu acredito que mais do que questionar a veracidade das conversões, ou a validade efetiva desse trabalho de evangelização, torna-se necessário atentar para os recursos que as denominações atuantes dentro da penitenciária em questão estão proporcionando, não em termos de recupera- 
ção do sujeito transgressor, mas como modo de proteção e tratamento dentro de um meio hostil e desorganizador das identidades como é o sistema prisional. O que os sistemas religiosos acabam proporcionando é uma inserção em uma dimensão simbólica daqueles sujeitos que o sistema, e, de resto, a própria sociedade, não tem capacidade ou interesse em integrar.

Certamente não se trata aqui de defender ou promover a atuação evangelizadora dentro das prisões, como meio de "salvação" ou "libertação" na linguagem êmica, ou, em uma linguagem sociológica, buscar a reintegração da mulher transgressora, trata-se de perceber que os meios utilizados por esses agentes religiosos talvez sirvam como uma matriz a partir da qual se possa pensar a ressocialização desses indivíduos.

A interação entre detentas e agentes religiosos aponta para uma necessidade urgente do sujeito preso de falar sobre os seus dramas e, através de uma narrativa, lidar com os limites que o sistema dominante lhe impóe dentro e fora da prisão.

\section{REFERENNCIAS}

BIRMAN, Patrícia. Cultos de possessão e pentecostalismo no Brasil: passagens. Religião e Sociedade, Rio de Janeiro: Iser, v. 17, n. 1-2, p. 90-108, 1996.

CARVALHO, José Jorge de. Caracterísitcas do fenômeno religioso na sociedade contemporânea. Brasília: UnB, 1991. (Série Antropologia).

FOUCAULT, Michel. A microfisica do poder. São Paulo: Difel, 1999.

GEERTZ, Clifford. A interpretação das culturas. Rio de Janeiro: LTC, 1989. RODRIGUES, Gilse Elisa. Negociando crenças: um estudo antropológico sobre conversão religiosa em uma penitenciária feminina. Dissertação (Mestrado em Antropologia Social)-PPGAS, Universidade Federal do Rio Grande do Sul, Porto Alegre, 2002.

GOFFMAN, Ervin. Manicômios, prisões e conventos. São Paulo: Perspectiva, 1978. 
HEFNER, Robert (Ed.). Conversion to Christianity: historical and anthropological perspectives on a great transformation. Los Angeles: University of California Press, 1993.

MAFRA, Clara. Relatos compartilhados: experiências de conversão ao pentecostalismo entre portugueses e brasileiros. Mana: estudos de antropologia social, Rio de Janeiro: Museu Nacional, v. 6, n. 1, p. 57-86, abr. 2000.

STEIL, Carlos Alberto. Catolicismo popular tradicional e Ação Pastoral:desafios e perspectivas no contexto da cultura contemporânea. Teocomunicação, Rio de Janeiro, n. 119, p. 87-104, 1998. 